\section{A Call for Data-Driven Networks to Address Equity in the Context of Undergraduate Biology}

\author{
Seth K. Thompson, ${ }^{+*}$ Sadie Hebert, ${ }^{\dagger}$ Sara Berk, ${ }^{\neq \S}$ Rebecca Brunelli," Catherine \\ Creech," Abby Grace Drake," Sheritta Fagbodun, ${ }^{\circledR}$ Marcos E. Garcia-Ojeda,** \\ Carrie Hall, ${ }^{+\dagger}$ Jordan Harshman, ${ }^{\neq \ddagger}$ Todd Lamb, ${ }^{*}$ Rachael Robnett, $\$ \$$ \\ Michèle Shuster, "II Sehoya Cotner, ${ }^{\dagger}$ and Cissy J. Ballen ${ }^{*}$ \\ 'Biology Teaching and Learning, University of Minnesota-Twin Cities, Minneapolis, MN 55455; \\ ”Biological Sciences, Auburn University and ${ }^{\ddagger}$ Chemistry and Biochemistry, Auburn University, \\ Auburn, AL 36849; "Biology, University of Washington, Seattle, WA 98195; "Biological Sciences, \\ California State University-Chico, Chico, CA 95929; 'Mt. Hood Community College, Gresham, \\ OR 97030; "Ecology and Evolutionary Biology, Cornell University, Ithaca, NY 14853; @Biology, \\ Tuskegee University, Tuskegee, AL 36088; **Quantitative and Systems Biology, University of \\ California-Merced, Merced, CA 95343; "Biological Sciences, University of New Hampshire, \\ Durham, NH 03824; ${ }^{\S}$ Psychology, University of Nevada-Las Vegas, Las Vegas, NV 89154; \\ "'Biology, New Mexico State University, Las Cruces, NM 88003
}

\begin{abstract}
National efforts to improve equitable teaching practices in biology education have led to an increase in research on the barriers to student participation and performance, as well as solutions for overcoming these barriers. Fewer studies have examined the extent to which the resulting data trends and effective strategies are generalizable across multiple contexts or are specific to individual classrooms, institutions, or geographic regions. To address gaps in our understanding, as well as to establish baseline information about students across contexts, a working group associated with a research coordination network (Equity and Diversity in Undergraduate STEM, EDU-STEM) convened in Las Vegas, Nevada, in November of 2019. We addressed the following objectives: 1) characterize the present state of equity and diversity in undergraduate biology education research; 2 ) address the value of a network of educators focused on science, technology, engineering, and mathematics equity; 3 ) summarize the status of data collection and results; 4 ) identify and prioritize questions and interventions for future collaboration; and 5) construct a recruitment plan that will further the efforts of the EDU-STEM research coordination network. The report that follows is a summary of the conclusions and future directions from our discussion.
\end{abstract}

\section{INTRODUCTION}

Science teaching in higher education faces many challenges, from inequitable student access to the social polarization of science (Gross, 2006; Mervis, 2011). In the context of undergraduate biology, these challenges are magnified by persistent gaps in performance and degree attainment among members of historically underrepresented groups (Trapani and Hale, 2019). Classroom challenges and institutional barriers impact members of underrepresented groups disproportionately and contribute to observed disparities in higher education (Allen, 1992; DesJardins et al., 2002). Investigations of these barriers for students should be expanded beyond the traditional venue of research-intensive institutions to include other learning environments that serve the large undergraduate population in the United States (Schinske et al., 2017). While a number of committed efforts show promise in promoting historically underserved groups (Wilson et al., 2012; Hernandez et al., 2013; Snyder et al., 2016; Theobald et al., 2020), deliberate evaluation across multiple institutional contexts will
CBE Life Sci Educ December 1, 2020 19:mr2 DOI:10.1187/cbe.20-05-0085

*Address correspondence to: Seth K. Thompson (thom2587@umn.edu).

(C) 2020 S. K. Thompson et al. CBE-Life Sciences Education (c) 2020 The American Society for Cell Biology. This article is distributed by The American Society for Cell Biology under license from the author(s). It is available to the public under an Attribution-Noncommercial-Share Alike 3.0 Unported Creative Commons License (http://creativecommons.org/licenses/ by-nc-sa/3.0).

"ASCB®" and "The American Society for Cell Biology®" are registered trademarks of The American Society for Cell Biology. 
rigorously assess when change occurs (or not) and inform recommendations for effective evidence-based practices.

To address research priorities, we convened a network of educators and discipline-based education researchers through a research coordination network (RCN) funded by the National Science Foundation (NSF) called Equity and Diversity in Undergraduate STEM (EDU-STEM). EDU-STEM integrates research and teaching in the context of evidence-based classroom experiences across biology curricula. The objectives of EDU-STEM are to: 1) reveal differences, if they exist, in the cultural climate for women and minoritized and marginalized groups in science, technology, engineering, and mathematics (STEM) disciplines (initially focusing on biology) as a function of geography, institution type, and cultural profile of the participating departments; (2) increase the number of faculty in the United States who are familiar with barriers to inclusion in STEM and can apply evidence-based techniques for countering known barriers; 3) develop a community of faculty who can serve as leaders - at their home institutions and nationally-in inclusive teaching and assessment; and 4) identify cultural factors associated with a shift toward evidence-based teaching, especially pertaining to inclusive teaching. In this paper, we present a framework for network activities developed during a meeting of EDU-STEM participants held in Las Vegas, Nevada, in November of 2019.

\section{EDU-STEM MEETING IN LAS VEGAS: INTEGRATING DIVERSE PERSPECTIVES}

We convened a meeting of 12 participants to 1 ) consider the current state of equity and diversity in STEM based on data generated from the incubator year of the grant; 2) reflect on the implications of our results and the value of the network; and 3) decide on future priorities for the network. To maximize our impacts, we invited faculty from community colleges (CCs), ${ }^{1}$ institutions with a minority-serving designation (MSIs), ${ }^{2}$ and research-intensive institutions (RIs) ${ }^{3}$ to attend the meeting. It was important that the network members present reflected the range of institutions integrated into the research network itself. In addition to a number of disciplinary biologists, the group also included discipline-based education researchers and psychologists interested in research on STEM equity and inclusion. Reflecting the diverse and extensive contributions of the network, both meeting participants and other network members are authors of this report. Detailed authorship contributions are provided in the authorship rubric document in the Supplemental Material.

\footnotetext{
${ }^{1}$ We define CCs as associate's colleges that offer training and classes that are affordable and relevant to the local community (Schinske et al., 2017; Carnegie Classification of Institutions of Higher Education, n.d.).

${ }^{2}$ MSIs are a federally recognized category of establishment based on minority student enrollment criteria. Examples include historically Black colleges and universities, predominantly Black institutions, Hispanic-serving institutions, Alaska Native and Native Hawaiian-serving institutions, Native American and Pacific Islander-serving institutions, and Tribal colleges and universities (Gasman et al. 2008).

${ }^{3}$ For the purposes of the research coordination network, we broadly define RIs as doctoral-granting institutions and master's-granting institutions without a minority-serving designation (Carnegie Classification of Institutions of Higher Education, n.d.).
}

The Equity and Diversity in Undergraduate STEM meeting took place on November 22-23, 2019, and aimed to achieve the following specific objectives:

1. Characterize the present state of equity and diversity in undergraduate biology education research (BER)

2. Address the value of a network of educators focused on STEM equity

3. Summarize the status of data collection and results

4. Identify and prioritize questions and interventions for future collaboration

5. Construct a recruitment plan that will further the goals of EDU-STEM

In the following sections, we describe the results from the meeting related to each of these objectives.

\section{What Is the Present State of Equity and Diversity in Undergraduate Biology Education Research?}

Calls for change in education to academically prepare an increasingly diverse student body led to a surge of empirical research on evidence-based teaching (American Association for the Advancement of Science, 2011). Discipline-based education journals such as CBE-Life Sciences Education, Microbiology \& Biology Education, and CourseSource and disciplinary biology journals such as PLoS ONE, PLoS Biology, BioScience, Proceedings of the Royal Society B: Biological Sciences, and Science actively publish BER focused on the undergraduate level.

Without caveats or limitations concerning the population under study, BER assumes students share some fundamental learning processes and that findings from one or a few student populations are applicable across contexts. Critics within other social science fields warn against universal claims about behavioral phenomena when research sampling is based on a single subpopulation, particularly if that pool of participants are from Western, educated, industrialized, rich, and democratic (WEIRD) societies (Henrich et al., 2010a). They argue that psychology (and other social sciences) often make broad statements about fundamental principles of human behavior, when in fact WEIRD populations may be among the most unusual people on Earth (Henrich et al., 2010b). Similarly, if the vast majority of subjects within discipline-based education research are primarily from selective, predominantly white institutions (PWIs), the experiences of students who are white, nondisabled, and middle to upper income will be overrepresented in the literature. Using the experiences of a privileged subset of students as the basis for broad generalizations only further promotes the pervasive dominance of the white experience and unjust power structures in our academic settings. A challenge moving forward for the field will be to test the generalizability of fundamental claims across different student populations.

Thus, one important contribution of EDU-STEM and similar networks is to provide a space to share experiences and develop effective teaching methods from institutions and student populations that are currently (and historically) underrepresented in BER. Furthermore, a network approach allows for the collaborative distribution of resources into institutions and student populations that are most impacted by educational disparities. During the meeting, we questioned the extent to which institutions serving underrepresented minorities (hereafter URMs; which include African-American, American 
Indian, Alaska Native, Hispanic/Latinx, underrepresented Asian-American, and other students of color) are represented in/producing the contemporary BER literature. We explored the extent that BER literature focuses on the experiences of students from single institutions, particularly doctoral-granting RIs. We extracted information from recent peer-reviewed literature from 2016, 2017, and 2018 in biology education across three journals ( $N=149$ articles). We collected data from CourseSource, a journal that publishes active-learning biology activities for the classroom and laboratories. We also selected two journals that commonly publish BER articles: CBE-Life Sciences Education and the Journal of Microbiology \& Biology Education. To narrow the scope of the inquiry, we focused on studies that addressed some element of active learning in the classroom within undergraduate biology. To do so, we searched for the term "active learning" in the titles, abstracts, or text of research articles and only included papers that focused empirically on pedagogical impacts.

From each article, we collected information such as whether the study focused on a single class or multiple class section(s) or courses (either over time or simultaneously), whether the study took place in one or multiple institution(s), whether the class size was greater or less than 50 students, and whether the focus was on upper- or lower-division classes. We define upper-division classes as those that require a prerequisite. Some papers did not explicitly state the university at which the work was completed; in these situations, we inferred that the study was conducted at the institution where $75 \%$ of the authors were working as long as the paper stated in the methods section the geographical range that met the location characteristics of the institution. To characterize institution type, we classified each institution as either a CC, a Baccalaureate Institution, MSI, a doctoral-granting RI, or a master's-granting RI. We used the Carnegie Classification of Institutions of Higher Education website (Carnegie Classification of Institutions of Higher Education, n.d.) to separate research-based institutions into doctoral-granting, master's-granting, or undergraduate universities. Then, we found minority-serving designations through the U.S. Department of the Interior website and reclassified those institutions as MSIs, regardless of their Carnegie Classification.

Our results mirror those from previous studies in BER (e.g., Schinske et al., 2017) and from the psychology literature, showing an overrepresentation of studies from relatively selective RIs ( $85 \%$ of studies); from single classes (62\% of studies) within single institutions (93\% of studies) that are composed of more than 50 students ( $77 \%$ of studies). Only five studies took place at MSIs (4\%), and three studies focused on CC populations (2\%; Figure 1). These findings present a critical challenge for the field of discipline-based education research, as the study participants included in most research are not representative of most college students. For example, CCs serve a large proportion of minority, first-generation (FGEN), low-income, and adult students (Ma and Baum, 2016). While MSIs educate 30\% of all U.S. undergraduates and produce $20 \%$ of the country's STEM bachelor's degrees (National Academies of Sciences, Engineering, and Medicine, 2019), only 4\% of all studies took place at MSIs. And while $42 \%$ of all undergraduates in the United States are enrolled in CCs (Ma and Baum, 2016), only $2 \%$ of BER studies about active learning took place at CCs. Among BER publications that do take place at CCs, Schinske

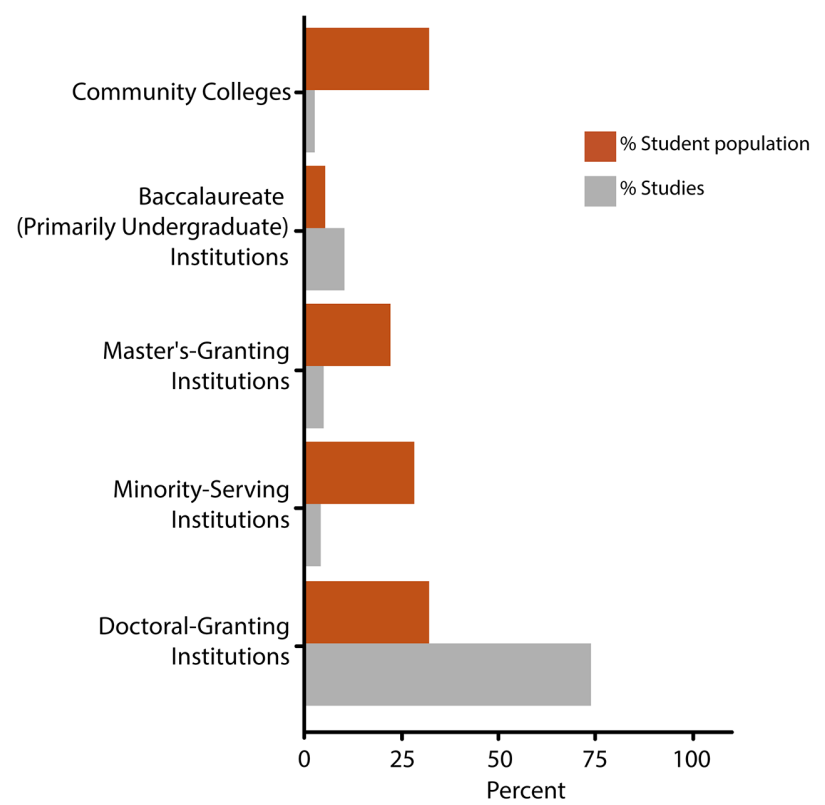

FIGURE 1. The percentage of the student population enrolled in institution types (orange) in the United States and the percentage of contemporary studies about evidence-based teaching that take place at those institutions (gray). Note the overrepresentation of students relative to education research studies at CCs, master's-granting institutions, and MSIs; and the overrepresentation of studies that take place at baccalaureate colleges and doctoral-granting institutions. Note that we pooled all schools that possess a minority-serving designation into one category; all other institutions lack this designation. References: Espinosa et al., 2017; Carnegie Classification of Institutions of Higher Education, n.d.

et al. (2017) reported more than half (51\%) of authorship came from individuals not affiliated with CCs. While CCs educate the majority of URM students, research on CC student populations rarely has an explicit focus on equity (Schinske et al., 2017). Such populations may stand to benefit most from research on evidence-based teaching with an emphasis on equitable teaching practices. Given that CCs and MSIs educate the majority of URM students, other institutions can learn from equitable teaching practices that are effective at these institutions. The unintentional mismatch between student populations studied in most BER and student populations enrolled in U.S. institutions of higher education could have important practical consequences as we investigate the largest barriers for students in higher education and develop recommendations for best teaching practices in "typical" college classrooms.

\section{Value of EDU-STEM: Large-Scale Collaboration Focused on Equity and Diversity}

EDU-STEM responds to the need to investigate different educational contexts by collaborating with faculty across different institutions and collecting data from a diversity of biology classrooms. As part of EDU-STEM, which has been collecting data from biology classrooms since 2015, we have identified barriers for students and the impacts of evidence-based teaching practices. For example, previous research has found that attrition rates among science majors appear to be highest for members 
of groups that have a history of underrepresentation in science fields (Seymour and Hewitt, 1994; Chen, 2013). According to recent work, disparities on the basis of race, ethnicity, gender, or FGEN status can be traced to a number of factors related to the classroom climate or the depersonalized, didactic atmosphere that characterizes many undergraduate science courses (Rainey et al., 2018). Learning environments are not only shaped by classrooms but also by institutional cultures, which create conditions wherein groups of people experience unequal opportunities. For example, the extent to which students report judgment from their peers and instructors on the basis of their race might differ based on institutional policies regarding equity and inclusion or the proportion of students who share those identities on campus or the extent that equitable teaching strategies are implemented in classrooms (Massey and Fischer, 2005; Johnson-Ahorlu, 2013). By developing and implementing innovations and reforms informed primarily by research conducted at a single type of institution, we overlook potent forces that likely differ between institution types.

Previous interventions that focus on equity and show promise in one course (e.g., introductory-level, advanced), in one STEM discipline (e.g., physics, biology), and in one setting (e.g., high school, college) may not translate to other instructional contexts. In fact, an intervention that is effective for a specific group of students could be less effective-or may even backfire-for students who have different background attributes (e.g., FGEN vs. continuing generation [CGEN]) or who are situated in a different educational context (e.g., CC vs. RI). In this vein, Steele (1997) cautions against taking a one size fits all approach to academic interventions. Instead, he argues that it is important to tailor interventions to the specific challenges that students encounter.

For example, results from previous studies show certain active-learning strategies reduce or eliminate demographic gaps in performance (Haak et al., 2011; Eddy and Hogan, 2014; Ballen et al., 2017). Until recently, the majority of research addressing this topic has been performed at large RIs and in single courses. Additionally, "active learning" is a broad term and is frequently undefined in the literature. Some active-learning practices increase student anxiety, potentially distracting from learning (England et al., 2017). And without paying explicit attention to equity, active learning can further disadvantage certain underrepresented student groups (Setren et al., 2019; Aguillon et al., 2020). Finally, social aspects of the classroom impact students in different ways, especially those students who tend toward introverted behavior (Beckerson et al., 2020), or who may feel pressure to conceal certain aspects of their identity, such as sexual orientation, political affiliation, or religion (Cooper and Brownell, 2016; Henning et al., 2019).

By leveraging complementary areas of expertise, science educators, psychologists, and data-management specialists can partner to avoid intervention pitfalls at scale. Science educators contribute a deep understanding of science pedagogy and the academic context; psychologists, on the other hand, are trained to identify the ways in which student attributes interact with the educational context to shape academic outcomes, providing insight into psychological mechanisms that account for an intervention's success (or lack thereof); and data-management specialists can help create platforms to assist in the broad interpretation of the results, informing personalized, evidence-based
TABLE 1. Summary of participating institutions included in the EDU-STEM RCN

\begin{tabular}{llc}
\hline Institution & \multicolumn{1}{c}{ Carnegie Classification } & MSI \\
\hline Institution A & Associate's Colleges & Yes \\
Institution B & Associate's Colleges & No \\
Institution C & Associate's Colleges & No \\
Institution D & Master's Colleges and Universities (M1) & Yes \\
Institution E & Master's Colleges and Universities (M2) & Yes \\
Institution F & Doctoral Universities (R1) & No \\
Institution G & Doctoral Universities (R2) & Yes \\
Institution H & Doctoral Universities (R1) & No \\
Institution I & Doctoral Universities (R1) & No \\
\hline
\end{tabular}

teaching practices and their dissemination to other faculty. EDU-STEM originated with a cohort including science educators, psychologists, and data-management experts and intends to grow representation in each of these categories.

\section{Summary of Data Collection and Results}

At the 2019 Las Vegas meeting, we discussed data that showed variability across institutions for a variety of student outcomes. The data included student-reported affective characteristics and demographic information collected from surveys and course performance data provided by instructors. The majority of the data was collected during Fall 2017 and Spring 2018 terms, but also included data from the Fall 2015, Spring 2016, Fall 2016, Spring 2017, and Fall 2018 terms. Nine participating institutions contributed information, representing three institution types according to the Basic Carnegie Classification of Institutions of Higher Education along with several designations of MSIs (Table 1).

The analysis (see Methods in the Supplemental Material) included data from 8740 students and confirmed differences across institution types for three student demographic characteristics: ${ }^{4}$ gender (female or male), underrepresented minority status (URM or non-URM), and college-going status (FGEN or CGEN). Proportions of female and male students, URM students, and FGEN students varied across institution types (Table 2). For the data collection, students and instructors had the option to omit survey items, which resulted in missing demographic data. Each broad demographic identity was

\footnotetext{
${ }^{4} \mathrm{~A}$ note about gender and race categories. For the purposes of this research, we use "male" and "female" to describe gender, recognizing that these refer to biological sex rather than gender. We use these terms, because they more accurately reflect the majority of the data we collected, which were institutional data that often only included binary options. We also use the term "underrepresented minority" to describe students who identify as American Indian/Alaska Native, Black/African American, Latinx/Hispanic/Hispanic American, and Native Hawaiian or Other Pacific Islander. This group excludes Asian/Asian-American and white/European-American individuals. We acknowledge this does not recognize the variation within and among groups. Some individuals in these groups do not identify with this term in a singular way, and some reject this term altogether. Overall a limitation of this research is the nature of these categories, which are problematic, because they are designated by an authority and do not leave room for or recognize people who identify as mixed race or outside the gender binary. Additionally, gender and race are only two of many human social identities that have subpopulations who are minoritized and underrepresented in biology. We plan to address this in the future by encouraging students to self-identify and expanding our categorical descriptors. While imperfect, our categories allow us to establish important baselines of student experiences in biology across institutions.
} 
collapsed for the purposes of this analysis, but we collected finegrained data on race/ethnicity identity and gender identity, because we realize both of these are complex. Students can identify with multiple racial/ethnic categories, and may identify with more than one gender, or may not identify with a gender.

We investigated differences across institution types for three demographic groups and multiple student outcomes. Here we will focus on two outcomes: survey measures of test anxiety and average exam performance. We measured test anxiety using four items from the Motivated Strategies for Learning Questionnaire (Pintrich, 1991). Across most institutions, females, on average, reported higher test anxiety than males (Figure 2A), and the difference between groups was statistically significant at three institutions (Figure 2, filled circles). URM students, on average, reported higher test anxiety than nonURM students at most institutions (Figure 2B), and the difference between groups was statistically significant at one institution (Figure 2B, filled circles). Interestingly, we found the opposite was true for some institutions. Across all institutions, FGEN students, on average, reported higher test anxiety than CGEN students (Figure 2C), and the difference between groups was statistically significant at one institution. With respect to weighted average exam percent, differences between males and females were highly variable among institutions. Males, on average, outperformed females at six of the institutions; while females, on average, outperformed males at three of the institutions; and the difference between groups was statistically significant at two institutions (Figure 3A). Across all institutions, non-URM students, on average, outperformed URM students, and the difference between groups was statistically significant at four institutions (Figure 3B). Across most institutions, CGEN students, on average, outperformed FGEN students, and the difference between groups was statistically significant at one institution (Figure 3C). In sum, we found evidence for significant performance gaps for multiple populations across multiple institution types, but the differences between groups are highly variable, demonstrating the need for expanded analysis.

Taken together, these results generated a robust discussion about how to interpret the findings and meaningful responses to observed patterns using large-scale collaboration. Following the discussion, several institutional leaders expressed an interest in text anxiety mitigation interventions. Together, this subgroup planned a two-semester exploration that involved: first, identifying whether test anxiety mediates performance, and whether this effect disproportionately impacts historically underserved students, as has been demonstrated by Ballen et al. (2017) and Salehi et al. (2019); and second, implementing a single intervention, in parallel across their institutions, in hopes of mitigating any demonstrated impacts of test anxiety (e.g., altering the balance of formative versus summative assessment; Cotner and Ballen, 2017). EDU-STEM funds will then allow these subgroup participants to meet to discuss their findings; if warranted, participants can also meet to draft manuscripts and develop nextstep plans for classroom interventions.

\section{Research Priorities for Future Collaboration}

What research questions are a large-scale collaborative network uniquely positioned to address? After a discussion of the strengths of a research network and the summary of our findings

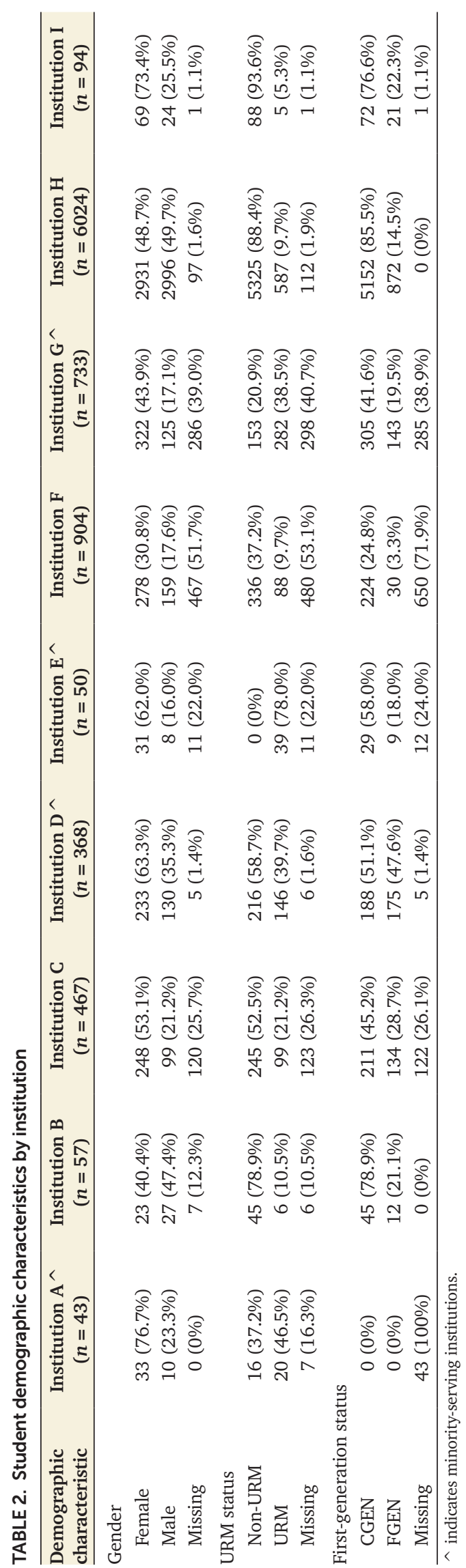


A

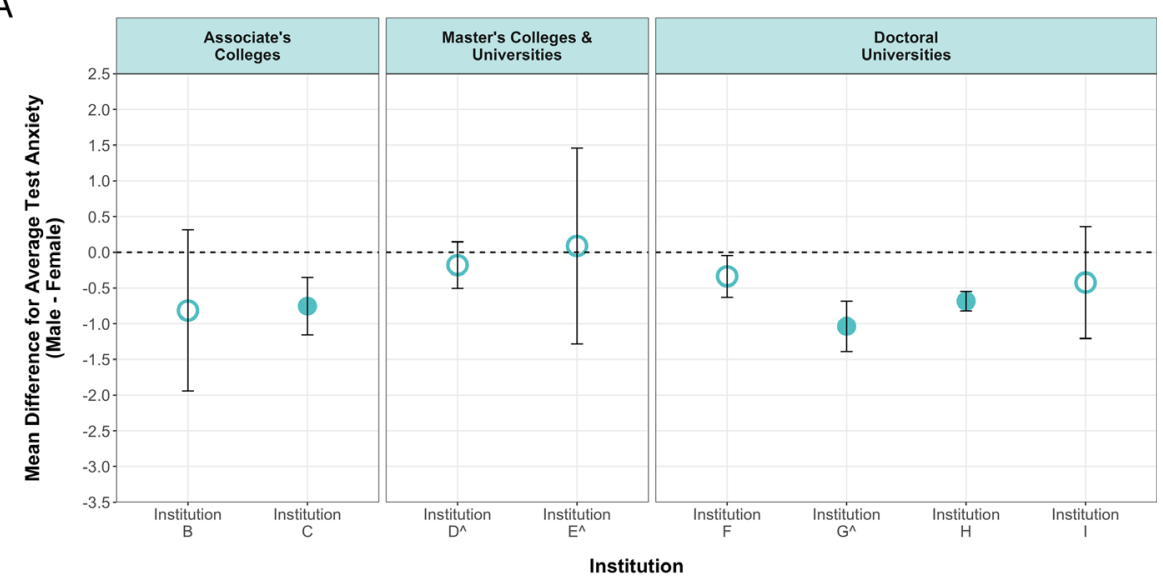

B

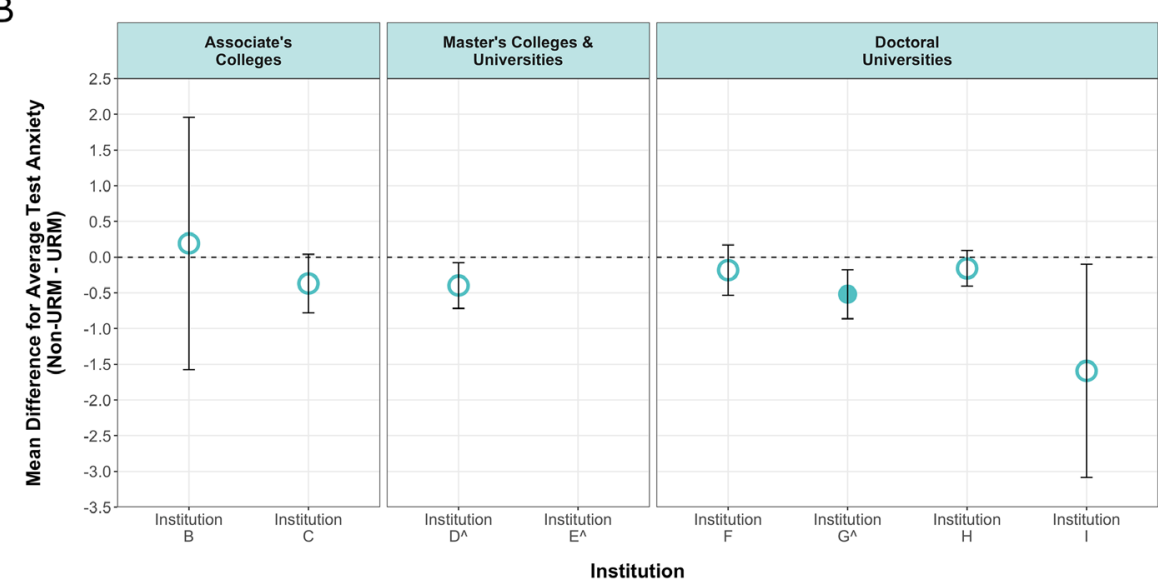

C

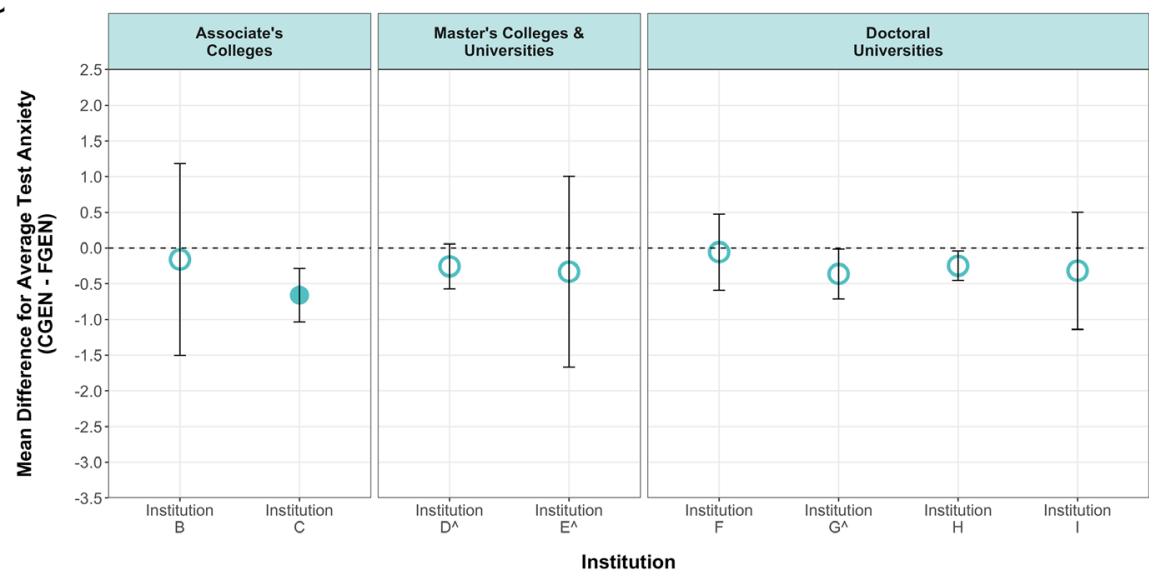

FIGURE 2. Mean differences for average test anxiety across institution type comparing (A) males and females, (B) non-URM and URM students, and (C) CGEN and FGEN students. In each panel, circles represent the differences between group means, and bars represent $95 \%$ confidence intervals for the differences between group means. Open circles indicate no significant difference between group means, and filled circles indicate a significant difference between group means. The dotted line represents no difference between groups. Measures below the dotted line indicate (A) females report higher anxiety than males; (B) URM students report higher anxiety than non-URM students; and (C) FGEN students report higher anxiety than CGEN students. MSIs are designated with ${ }^{\wedge} \wedge$. A list of deidentified institutions is shown in Table 1. to date, we identified two research priorities for EDU-STEM moving ahead: 1) context-dependent identity salience, or how salient elements of one's identity impact classroom experiences across different learning contexts; and 2) intersectionality, in which constructs such as race and gender interact with one another and with other social categories (e.g., class background) to shape people's experiences in everyday life (Crenshaw, 1989; hooks, 2000). We selected these as worthy research pursuits, because they have direct consequences for student learning and equity, and can be robustly addressed through a collaborative network. We expand on those discussions through a brief literature review of these priorities and develop a case for why collaborative research networks, like EDUSTEM, are poised to address them.

Context-Dependent Identity Salience. Data collected through the EDU-STEM Network provide a unique opportunity to examine how social identities such as race/ethnicity and gender work together to shape students' experiences across institutions of higher education. Research shows that students who identify as URM and women are more likely to experience challenges in STEM higher education settings, but these challenges are documented in largely separate literatures. Research focusing on racial/ethnic disparities indicates that URM students are often underserved in the K-12 education system (Lee and Ransom, 2011; Sáenz and Ponjuan, 2011), which can make for a difficult transition to undergraduate STEM course work. Further, URM students are more likely than white students to be FGEN college students, which can compound other challenges, such as feelings of low belongingness or negative stereotypes about academic ability (Lohfink and Paulsen, 2005). In contrast, research focusing on gender disparities in STEM often focuses on gendered social role expectations. Women inhabit a social system that steers them toward communal careers and roles, which are often perceived as incompatible with STEM achievement (Diekman and Steinberg, 2013). In addition, undergraduate women in STEM contexts report encountering 
A

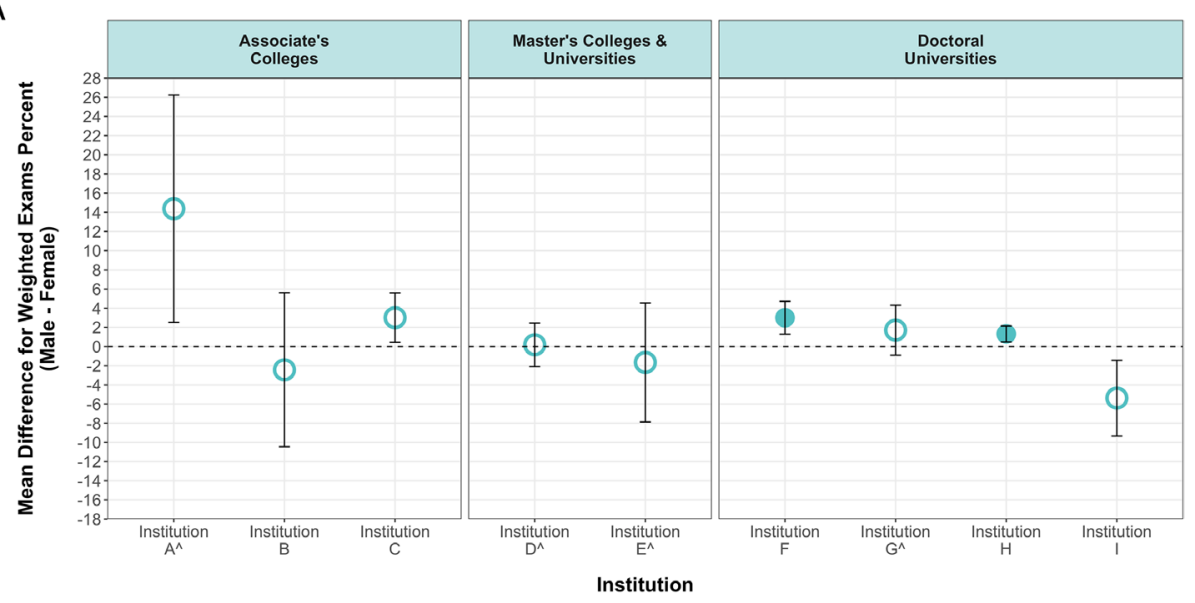

B

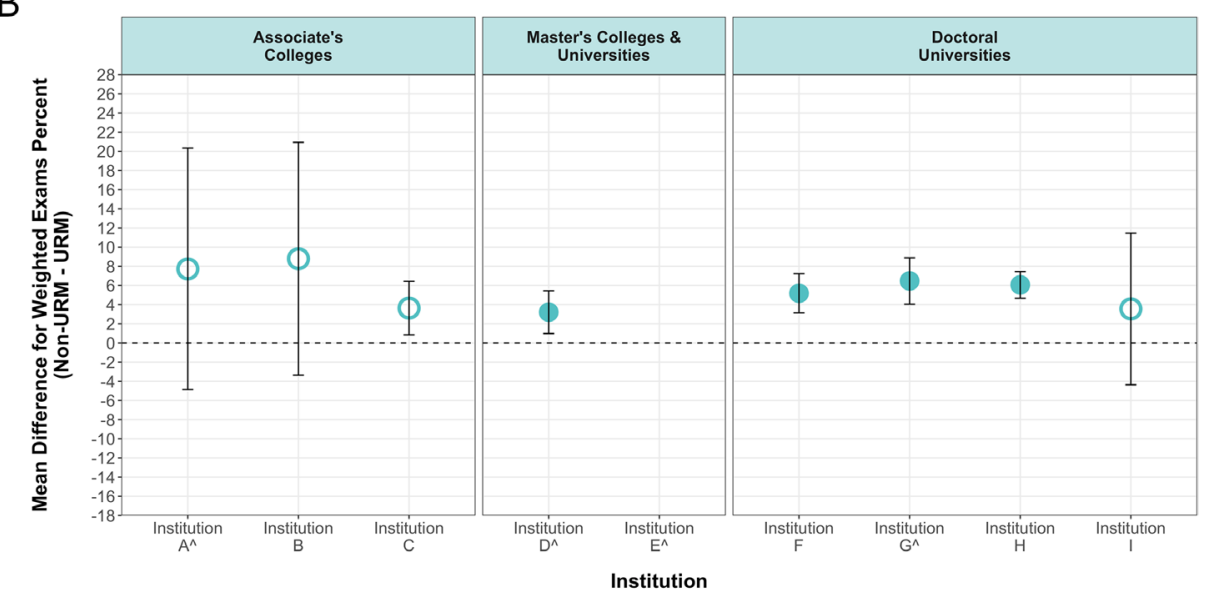

C

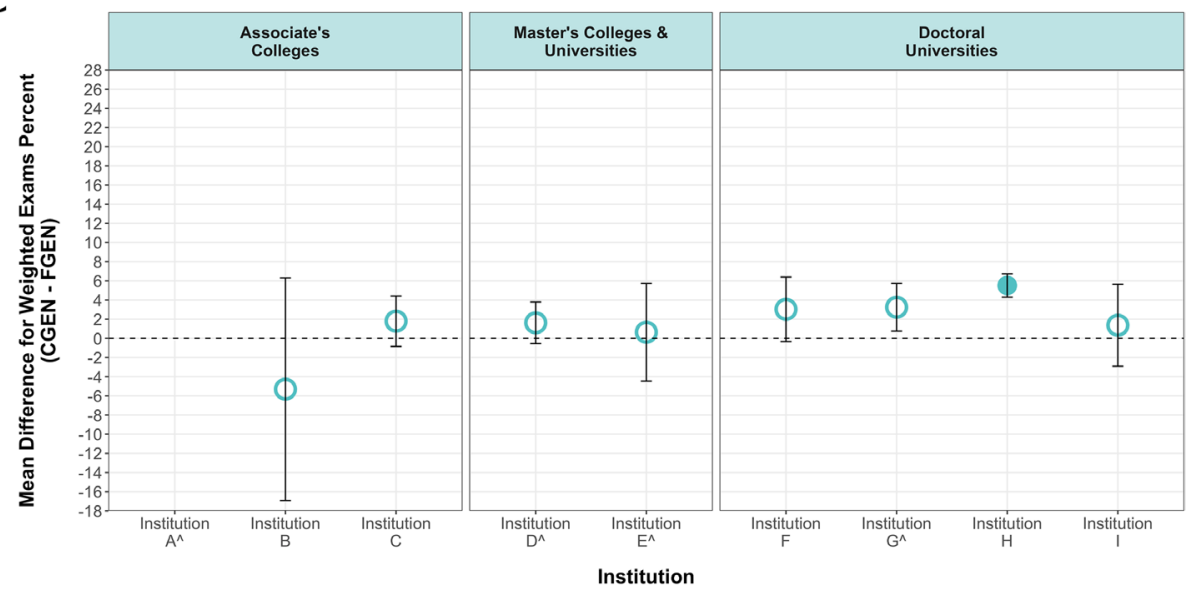

FIGURE 3. Mean differences for weighted exam performance across institution type comparing (A) males and females, (B) non-URM and URM students, and (C) CGEN and FGEN students. In each panel, circles represent the differences between group means, and bars represent $95 \%$ confidence intervals for the differences between group means. Open circles indicate no significant difference between group means, and filled circles indicate a significant difference between group means. The dotted line represents no difference between groups. Measures above the dotted line indicate (A) males outperform females; (B) non-URM students outperform URM students; and (C) CGEN students outperform FGEN students. MSIs are designated with a $\wedge$. negative stereotypes about their academic ability, social isolation, and sexism from other students and faculty (Hill et al., 2010; Robnett, 2016). They also report lower STEM self-efficacy than their male counterparts, even when actual academic performance is held constant (Robnett and Thoman, 2017; Marshman et al., 2018).

We also realize the importance of institutional factors beyond the broad categorizations we mention here. Institutional transformation to evidence-based teaching and learning that is inclusive and equitable requires a systems-level analysis of the current behavior of the institution to understand: 1) where the problems lie, and 2) what changes are necessary to realize inclusive transformation. As faculty and institutions strive to improve biology education, we will use Nadler and Tushman's (1980) congruence model of organizational behavior as a framework to guide and evaluate institutional change as it occurs on the campuses of this network. The model posits that high congruence, or fit, among four factors that make up an organization-the task, the people, the formal organizational structure, and the culture-will positively impact behavior and performance. Thus, when observed outcomes do not align with desired outcomes, analyzing the congruency between the four components provides insight into areas within the organization where changes need to be made. By using the congruence model to understand where problems lie, RCN institutions can implement changes that are necessary to realize desired outcomes.

Intersectionality in Higher Education. Women of color encounter a combination of the aforementioned challenges as well as unique challenges that cannot be understood through their ethnicity or gender alone (Ong et al., 2011; Williams et al., 2014). The concept of intersectionality provides a framework for understanding these challenges. Some scholars argue that attaining a deep understanding of inequities in STEM fields requires consideration 
of the ways in which social categories combine to create distinct identity configurations (e.g., Ong et al., 2011). In an undergraduate biology course, for example, a Latinx woman and a white woman may both encounter challenges related to gender, but the specific nature of these challenges and their implications may differ in meaningful regards.

EDU-STEM is well positioned to build on past work that applies the concept of intersectionality to the study of STEM disparities. Beyond diversity in the students and institutions comprising the sample, diversity within EDU-STEM itself (i.e., in terms of sociodemographic background and home institution) allows for multifaceted input into which research questions to prioritize and how to interpret core findings. We elaborate on key research priorities related to intersectionality that surfaced during our meeting.

Most of the existing research that applies an intersectional framework is qualitative and relies on small sample sizes from single institutions. Although this work is important and useful in its own right (e.g., Carlone and Johnson, 2007), it is also critical for larger quantitative studies to be included in the intersectionality literature. For instance, relative to qualitative research, quantitative studies allow for more formal hypothesis testing, the ability to statistically control for potential confounds, and clearer insight into the magnitude of group differences. Prior research is also limited, in that it has not made use of the full power of intersectionality. Specifically, a fair number of qualitative studies have focused on women of color in STEM (for a review, see Ong et al., 2011), but little is known about how their experiences compare with the experiences of students from other backgrounds (e.g., men of color, white women). When such comparisons are conducted, sample size requirements often limit researchers to coarse ethnic groupings (e.g., lumping all URM students into the same category) and make it difficult to take into account more than two dimensions of identity (e.g., Robnett et al., 2019).

The EDU-STEM data can be used in several ways to address these limitations. One possibility is a quantitative "deep dive" into the experiences of students who have often been overlooked in smaller-scale studies. For example, it would be worthwhile to examine whether the factors that predict academic success among Latinx men differ depending on whether the men are FGEN versus CGEN college students. Alternatively, the EDU-STEM data could also be used to cast a wider intersectional net. For example, we could compare mean levels of self-efficacy across all possible configurations of ethnicity, gender, and class background. This would provide insight into whether commonplace research findings (e.g., the finding that women have lower self-efficacy than men) hold across more complex identity configurations. More broadly, the EDU-STEM data can provide insight into how various facets of identity interact with the institutional context to shape student outcomes. For example, an African-American woman may have qualitatively different experiences in her biology class depending on whether she is enrolled at a PWI versus a historically black college or university.

It is important to emphasize, however, that EDU-STEM needs to be wary of reducing complex identity configurations to statistical interaction terms. We need to be mindful of the ways in which identity interacts with currents of privilege and power in the broader social context. Relatedly, at its core, the intersec- tionality framework is oriented toward fostering change by equalizing power imbalances that are often obscured by less-nuanced approaches. In this regard, the concept of intersectionality has clear implications for academic interventions that aim to reduce sociodemographic disparities in STEM engagement and performance. For example, if a woman of color and a white woman experience distinct challenges in their biology course, it follows that they may benefit from different types of interventions. Thus, in addition to documenting how student experiences vary at the intersection of multiple social categories, the intersectionality framework can help educators and researchers move beyond one size fits all interventions by informing the development of targeted interventions that optimize success for all students.

\section{How to Grow the Network: A Recruitment Plan to Further the Goals of EDU-STEM}

EDU-STEM was founded on the principle of increasing the literature representation of the student experience. Therefore, a major outcome of our meeting was the development of a recruitment plan for growing the network in the future. EDUSTEM aims to grow its membership by leveraging the personal relationships of network members to integrate new participants within existing institutional partnerships while broadening the network to include new institutional partners. Using a reciprocal partnership model as our guiding framework, EDUSTEM aims to cultivate a community that honors the contribution of all members and acknowledges the strengths and expertise that each partner brings to the table. In this sense, EDU-STEM is not about providing RIs with access to student populations at other institution types, instead it is about building relationships that allow different partners to best capitalize on the shared expertise and resources of the EDU-STEM membership. By involving a range of educators and researchers from a diverse set of institutions in collecting their own data on equity in STEM, this network will establish tendrils of equity awareness among groups of faculty not typically engaged in educational research or evidence-based teaching techniques. To achieve this, we will focus on two recruitment aims: 1) developing institutional capacity by recruiting a team of network participants from each partner institution and 2) growing institutional representation by recruiting new network participants from institutions that have been underrepresented in the literature.

Developing Institutional Capacity. Taking on the work of educational reform can be challenging if it is seen as a solo effort. EDU-STEM hopes to alleviate some of that challenge by cultivating communities of committed instructors within our partner institutions. By identifying an institutional lead (or two) at each of our partner institutions and then providing support for those leads to engage with other members of their institutions, EDU-STEM aims to support local communities that collectively contribute to the national group. EDU-STEM supports this local cultivation by providing travel support to meetings for network partners, curating opportunities for professional development around issues of equity and inclusion, and designing classroom-level interventions that are supported by the national network and available for all network partners to implement in their classrooms. 
TABLE 3. Specific ways in which collaborative networks can promote and maintain partnerships with CCs and MSIs, institutions that are historically underrepresented in BER

\begin{tabular}{|c|c|}
\hline Core network principles & Recommended practices \\
\hline $\begin{array}{l}\text { Authentic partnerships } \\
\text { Partnerships should be based on } \\
\text { opportunities for collaborations that } \\
\text { are mutually beneficial for all } \\
\text { participants. }\end{array}$ & $\begin{array}{l}\text { Enable reciprocal exchange of ideas that create new value together rather than a transfer of resources } \\
\text { from one partner to another. } \\
\text { Deconstruct hierarchies to create opportunities for meaningful participation from multiple contexts. } \\
\text { Facilitate opportunities for structured dialogue and shared learning to promote a commitment to } \\
\text { creating common understandings. } \\
\text { Provide pathways for constructive feedback and establish shared norms for giving and receiving } \\
\text { feedback. }\end{array}$ \\
\hline $\begin{array}{l}\text { Facilitate targeted recruitment efforts } \\
\text { for underrepresented communities } \\
\text { by building relationships built on } \\
\text { trust and shared commitments. }\end{array}$ & $\begin{array}{l}\text { Put personal relationship building at the front of conversations on partnership and emphasize shared } \\
\text { ownership to promote trust. } \\
\text { Personalize recruitment efforts to highlight the specific value added by a potential network member, } \\
\text { including a commitment to shared values. }\end{array}$ \\
\hline $\begin{array}{l}\text { Public campaign to broaden access } \\
\text { to network activities } \\
\text { Make the network activities widely } \\
\text { known by presenting at meetings, } \\
\text { establishing a consistent brand } \\
\text { identity, and maintaining a Web } \\
\text { presence. }\end{array}$ & $\begin{array}{l}\text { Make it easy for others to find out about you and your work. } \\
\text { Establish a consistent brand identity and provide network members with recruitment materials } \\
\text { (business cards, flyers, slides, etc.) that can be easily distributed to broad audiences. } \\
\text { Host or sponsor professional development opportunities that build capacity and broaden knowledge for } \\
\text { network participation. } \\
\text { Have an application process in place to ensure that network membership remains in line with the } \\
\text { network principles. }\end{array}$ \\
\hline $\begin{array}{l}\text { Incentivize and support network } \\
\text { participation } \\
\text { Honor the time and effort committed } \\
\text { by network members in ways that } \\
\text { meet their professional and } \\
\text { personal needs. }\end{array}$ & $\begin{array}{l}\text { Create clear guidelines for opportunities to participate in collaborative manuscripts, grants, meetings, } \\
\text { and workshops. } \\
\text { Provide funding support for participating in network events and create a process for the equitable } \\
\text { distribution of available funds. } \\
\text { Host network activities in a variety of locations to encourage participation from a greater number of } \\
\text { network members and promote shared ownership. } \\
\text { Use the network to lift up and advance the work of members in career stage-relevant ways; promote } \\
\text { leadership opportunities for early-career researchers and students; and cultivate professional } \\
\text { networking. }\end{array}$ \\
\hline
\end{tabular}

Inclusive Network Growth. How do we grow a research network with institutions that have been historically underrepresented in the literature? Diversity in science refers to cultivating talent and promoting the full inclusion of excellence across the social spectrum, including people from backgrounds that are traditionally underrepresented (Gibbs, 2014). From the perspective of inquiry, given that CCs and MSIs are leaders in successfully graduating URMs in STEM as well as matriculating them into graduate STEM academic programs (Fiegener and Proudfoot, 2013), few studies have been published that show or explain what these institutions are doing to be successful at educating underrepresented students. Via network involvement, CC and MSI faculty can contribute to emerging literature on promoting equitable participation in STEM. In the meeting, we discussed ways that the network can foster authentic, equitable partnerships with leaders at CCs and MSIs (outlined in Table 3) to better support the work of these scholars and provide opportunities for leadership that are responsive to the unique needs of these institutions.

Authentic Partnership. A core belief of the EDU-STEM network is that an effective network offers the opportunity for the creation of authentic partnerships, involving collaborations that mutually benefit the participants and participants' institutions and that create value together. Equitable participation can be enhanced via transparency at each step of the process. To that end, EDU-STEM participants decided to create and submit to consensus the following items in support of the network:
- a Principles of Operation document, clarifying shared terminology (e.g., STEM, MSI, PWI, gender, etc.)

- an authorship rubric, establishing criteria for involvement and allowing individuals to commit to different roles during manuscript development

- a project-submission process, whereby network members can "plant a flag" in a particular, specific, line of inquiry that draws on EDU-STEM data; any network member may join any project and contribute to resulting manuscripts, a formal process for proposing projects will prevent unnecessary duplication of efforts, provide members with a known point of contact, and promote accountability

- working groups, open to all members, with a specific charge, rotating leadership, and annual goals and objectives (e.g., data-management working group, network expansion working group)

By democratizing the organizational structure and encouraging participation that best leverages the experience, skills, and commitments of each individual member, EDU-STEM hopes to grow a collaborative network in a way that can promote equitable collaborations and sustainable partnerships.

Targeted Recruitment Activities. The goal of targeted recruitment within EDU-STEM is to ensure that traditionally excluded communities have access to network activities. During our meeting, there was a lengthy discussion about the need to recruit members in a way that is not exploitative and emphasizes trust, given that many minoritized populations have been 
subjected to exploitative relationships in the past. To this end, we have codified relationship building as the primary method for growing partnerships and encouraged collective decision making. We have asked our institutional leaders to serve as advocates within their own communities and to work to communicate with institutional leaders by sending emails, letters, brochures, and posters to deans and department chairs at MSIs, CCs, and other underrepresented institutions to recruit participants. By empowering and supporting current network members to take on leadership for targeted recruitment efforts, we hope to enhance the authenticity and credibility of efforts working toward a more inclusive STEM community.

Publicize the Network. In addition to our targeted recruitment, establishing an application process for a broader-based recruitment effort was a key priority coming out of the inaugural meeting. To achieve this, we proposed a three-pronged approach. First, we plan to recruit at meetings and poster sessions at local, regional, and national conferences. We will ask current network participants to represent the network at meetings they attend, particularly those attending meetings with a high attendance of underrepresented institutions and students (i.e., Annual Biomedical Research Conference for Minority Students, Southern Region Education Board, Emerging Researchers National Conference in STEM, Society for Advancement of Chicanos and Native Americans in Science).

In addition to recruitment efforts at meetings, we plan to host professional development opportunities that help build capacity and broaden the knowledge base of BER and broaden participation in research for BER faculty and non-BER faculty at MSIs and CCs. These efforts will include EDU-STEM participants giving guest lectures and EDU-STEM-designed professional development opportunities (workshops/seminars, virtual or in person). Through these supported opportunities, EDU-STEM will help cultivate a community of faculty from a variety of instruction types that have both the training and support to increase the implementation of evidence-based pedagogy and interventions.

Finally, EDU-STEM has partnered with the University of Minnesota's Impact Exchange (http://z.umn.edu/impactexchange) to develop a consistent network brand identity and online Web presence. Through this partnership, we will work with an undergraduate student intern who is receiving professional development in science communication and design through the Impact Exchange to create professional-quality recruitment materials (i.e., EDU-STEM give-aways) and to centrally manage the network's social media and website to inform potential participants about our network and maintain consistent network branding and messaging. We believe this will be an important part of developing a sustainable recruitment strategy, because it will allow for all network members to speak about the network in a consistent way and will empower members to take on recruitment efforts knowing they have the support of curated materials provided to them.

Incentivize Network Participation. Perhaps most important to our recruitment efforts and support of EDU-STEM is the acknowledgment that a traditional approach of relying on completely volunteer participation in activities will systematically exclude those with more limited access to resources. To move away from this model and to promote as much access to our network activities as possible, we are committed to providing access to resources that facilitate the dissemination of participant and network products, such as travel funds to participate in educational conferences and funds for the dissemination of educational publications. We are committed to leveraging network resources to particularly support members at critical career transitions (e.g., senior graduate students, postdocs, pre-tenure faculty). With access to network expertise and collaborations, members can leverage their network participation to successfully navigate key career transitions. Through our coordinated data-collection and intervention efforts, we anticipate that there will be huge potential for research output from the network, both through collaborative research proposals and collaborative manuscripts. Our goal is to make these activities accessible to all members of the network, particularly for those who may need to rely on such collaborations to be active/successful participants in BER.

Call for New Participants. If you have a passion for educational reform to promote more equitable STEM disciplines and want to get involved with the EDU-STEM network, we want to hear from you! You can find more information about the network and fill out an interest form on our website (edustemresearch.com). There you will find information about the current network members, ongoing network activities, and a link to sign up for the EDU-STEM newsletter. While the current focus of the network is confined to biology curricula based on the expertise of current network members, the future growth of the network welcomes participants from any STEM discipline. If you are looking to get involved or have any questions, reach out to us at edustemcontact@gmail.com, follow us on Twitter@ EDUSTEMNetwork, or apply for network membership using this Google form (https://docs.google.com/forms/d/e/ 1FAIpQLSeV6mBgd1cTCB6ya85buWe9TFjWNm3DGXwSsLOeE _dW4C_I8A/viewform). We have also included an example of a recruitment letter in the Supplemental Material. Individual partners can best be reached through their institutions.

EDU-STEM members will be present at several national and international meetings over the coming years, so be sure to ask members about the network. Also, we will host an annual meeting each year directly preceding the Society for the Advancement of Biology Education Research meeting in July. If you are interested in attending the annual meeting, contact us via the webform and we will make sure you get added to the mailing list. Finally, we are putting together regular opportunities (semiannual to quarterly) for network members to connect virtually to continue conversations on projects and interventions.

\section{CONCLUSION}

It is important to note that EDU-STEM is not the only collaborative group working to promote equity and inclusion in undergraduate STEM. Additional examples include (but are not limited to) the Accelerating Systemic Change Network, the Association of American Universities Undergraduate STEM Education Initiative, the iEmber Network, the Association of American Colleges and Universities Undergraduate STEM Education initiative, and the Howard Hughes Medical Institute 
Inclusive Excellence community. Through inclusive collaboration, we will gain insight into perspectives and address questions that would not be achievable otherwise. The Equity and Diversity in Undergraduate STEM meeting explored ideas about the present state of equity in undergraduate biology education, the largest barriers faced by institutions, and how a large-scale collaborative can contribute to the development of solutions through data generation and experimental efforts. We welcome interest from all members of the community and look forward to hearing from you!

\section{ACKNOWLEDGMENTS}

Samantha Brandt at University of Minnesota provided invaluable logistical and creative support for the meeting. We would also like to thank the Psychology Department at University of Nevada, Las Vegas, for hosting our meeting. This work was supported by a RCN grant from the NSF (DBI-1919462). Any opinions, findings, conclusions, and recommendations expressed in this material are those of the authors and do not necessarily reflect the views of the NSF.

\section{REFERENCES}

Aguillon, S. M., Siegmund, G.-F., Petipas, R. H., Drake, A. G., Cotner, S., \& Ballen, C. J. (2020). Gender differences in student participation in an active-learning classroom. CBE-Life Sciences Education, 19(2), ar12.

Allen, W. (1992). The color of success: African-American college student outcomes at predominantly white and historically black public colleges and universities. Harvard Educational Review. https://doi.org/10.17763/ haer.62.1.wv5627665007v701

American Association for the Advancement of Science. (2011). Vision and change in undergraduate biology education: A call to action. Washington, DC.

Ballen, C. J., Salehi, S., \& Cotner, S. (2017). Exams disadvantage women in introductory biology. PLOS ONE, 12(10), e0186419.

Ballen, C. J., Wieman, C., Salehi, S., Searle, J. B., \& Zamudio, K. R. (2017). Enhancing diversity in undergraduate science: Self-efficacy drives performance gains with active learning. CBE-Life Sciences Education, 16(4), $\operatorname{ar} 56$.

Beckerson, W. C., Anderson, J. O., Perpich, J. D., \& Yoder-Himes, D. (2020). An introvert's perspective: Analyzing the impact of active learning on multiple levels of class social personalities in an upper level biology course. Journal of College Science Teaching, 49(3), 47-57.

Carlone, H. B., \& Johnson, A. (2007). Understanding the science experiences of successful women of color: Science identity as an analytic lens. Journal of Research in Science Teaching, 44(8), 1187-1218.

Carnegie Classification of Institutions of Higher Education. (n.d.). About Carnegie Classification. Retrieved April 23, 2020, from http://carnegieclassifications iu.edu/

Chen, X. (2013). STEM attrition: College students' paths into and out of STEM fields (Statistical Analysis Report NCES 2014-001). Washington, DC: National Center for Education Statistics.

Cooper, K. M., \& Brownell, S. E. (2016). Coming out in class: Challenges and benefits of active learning in a biology classroom for LGBTQIA students. CBE-Life Sciences Education, 15(3), ar37.

Cotner, S., \& Ballen, C. J. (2017). Can mixed assessment methods make biology classes more equitable? PLOS ONE, 12(12). https://doi.org/10.1371/ journal.pone.0189610

Crenshaw, K. (1989). Demarginalizing the intersection of race and sex: A black feminist critique of antidiscrimination doctrine, feminist theory and antiracist politics. University of Chicago Legal Forum, 1989, ar8.

DesJardins, S. L., Ahlburg, D. A., \& McCall, B. P. (2002). A temporal investigation of factors related to timely degree completion. Journal of Higher Education, 73(5), 555-581. https://doi.org/10.1353/jhe.2002.0042

Diekman, A. B., \& Steinberg, M. (2013). Navigating social roles in pursuit of important goals: A communal goal congruity account of STEM pursuits. Social and Personality Psychology Compass, 7(7), 487-501.
Eddy, S. L., \& Hogan, K. A. (2014). Getting under the hood: How and for whom does increasing course structure work? CBE-Life Sciences Education, 13(3), 453-468.

England, B. J., Brigati, J. R., \& Schussler, E. E. (2017). Student anxiety in introductory biology classrooms: Perceptions about active learning and persistence in the major. PLoS One, 12(8), e0182506.

Espinosa, L. L., Turk, J. M., \& Taylor, M. (2017). Pulling back the curtain: Enrollment and outcomes at minority serving institutions. Washington, DC: American Council on Education.

Fiegener, M. K., \& Proudfoot, S. L. (2013). Baccalaureate origins of US-trained S\&E doctorate recipients. Arlington, VA: National Science Foundation. Retrieved August 27, 2020, from https://nsf.gov/statistics/infbrief/ nsf13323/nsf13323.pdf

Gasman, M., Baez, B., \& Turner, C. S. V. (2008). Understanding minority-serving institutions. Albany, NY: SUNY Press.

Gibbs, K. (2014). Diversity in STEM: What it is and why it matters. Scientific American, 10. Retrieved August 27, 2020, from https://blogs.scientificamerican .com/voices/diversity-in-stem-what-it-is-and-why-it-matters/

Gross, L. (2006). Scientific illiteracy and the partisan takeover of biology PLOS Biology, 4(5), e167.

Haak, D. C., HilleRisLambers, J., Pitre, E., \& Freeman, S. (2011). Increased structure and active learning reduce the achievement gap in introductory biology. Science, 332(6034), 1213-1216. https://doi.org/10.1126/ science. 1204820

Henning, J. A., Ballen, C. J., Molina, S., \& Cotner, S. (2019). Hidden identities shape student perceptions of active learning environments. Frontiers in Education, 4, 129.

Henrich, J., Heine, S. J., \& Norenzayan, A. (2010a). Most people are not WEIRD. Nature, 466(7302), 29

Henrich, J., Heine, S. J., \& Norenzayan, A. (2010b). The weirdest people in the world? Behavioral and Brain Sciences, 33(2-3), 61-83.

Hernandez, P. R., Schultz, P. W., Estrada, M., Woodcock, A., \& Chance, R. C. (2013). Sustaining optimal motivation: A longitudinal analysis of interventions to broaden participation of underrepresented students in STEM Journal of Educational Psychology, 105(1). https://doi.org/10.1037/ a0029691

Hill, C., Corbett, C., \& St Rose, A. (2010). Why so few? Women in science, technology, engineering, and mathematics. Washington, DC: AAUW.

hooks, b. (2000). Feminist theory: From margin to center. London: Pluto Press.

Johnson-Ahorlu, R. N. (2013). "Our biggest challenge is stereotypes": Understanding stereotype threat and the academic experiences of African American undergraduates. Journal of Negro Education, 82(4), 382-392.

Lee, J. M., Jr, \& Ransom, T. (2011). The educational experience of young men of color: A review of research, pathways and progress. College Board Advocacy \& Policy Center. Retrieved August 27, 2020, from https://eric ed.gov/?id=ED521425

Lohfink, M. M., \& Paulsen, M. B. (2005). Comparing the determinants of persistence for first-generation and continuing-generation students. Journal of College Student Development, 46(4), 409-428.

Ma, J., \& Baum, S. (2016). Trends in community colleges: Enrollment, prices student debt, and completion. College Board Research Brief, 4, 1-23.

Marshman, E. M., Kalender, Z. Y., Nokes-Malach, T., Schunn, C., \& Singh, C. (2018). Female students with A's have similar physics self-efficacy as male students with C's in introductory courses: A cause for alarm? Physical review physics education research, 14(2), 020123.

Massey, D. S., \& Fischer, M. J. (2005). Stereotype threat and academic performance: New findings from a racially diverse sample of college freshmen. DuBoisReview, 2(1), 45-67.https://doi.org/10.1017/S1742058X05050058

Mervis, J. (2011). Weed-out courses hamper diversity. Science, 334(6061), 1333

Nadler, D. A., \& Tushman, M. L. (1980). A model for diagnosing organizational behavior. Organizational Dynamics, 9(2), 35-51.

National Academies of Sciences, Engineering, and Medicine. (2019). Minority serving institutions: America's underutilized resource for strengthening the STEM workforce. Washington, DC: National Academies Press.

Ong, M., Wright, C., Espinosa, L., \& Orfield, G. (2011). Inside the double bind: A synthesis of empirical research on undergraduate and graduate wom- 


\section{S. K. Thompson et al.}

en of color in science, technology, engineering, and mathematics. Harvard Educational Review, 81(2), 172-209.

Pintrich, P. R. (1991). A manual for the use of the Motivated Strategies for Learning Questionnaire (MSLQ). Retrieved August 27, 2020, from https:// eric.ed.gov/?id=ED338122

Rainey, K., Dancy, M., Mickelson, R., Stearns, E., \& Moller, S. (2018). Race and gender differences in how sense of belonging influences decisions to major in STEM. International Journal of STEM Education, 5(1), 10.

Robnett, R. D. (2016). Gender bias in STEM fields: Variation in prevalence and links to STEM self-concept. Psychology of Women Quarterly, 40(1), 65-79.

Robnett, R. D., Nelson, P. A., Zurbriggen, E. L., Crosby, F. J., \& Chemers, M. M. (2019). The form and function of STEM research mentoring: $A$ mixed-methods analysis focusing on ethnically diverse undergraduates and their mentors. Emerging Adulthood, 7(3), 180-193.

Robnett, R. D., \& Thoman, S. E. (2017). STEM success expectancies and achievement among women in STEM majors. Journal of Applied Developmental Psychology, 52, 91-100.

Sáenz, V. B., \& Ponjuan, L. (2011). Men of color: Ensuring the academic success of Latino males in higher education. Institute for Higher Education Policy. Retrieved August 27, 2020, from https://eric.ed.gov/?id=ED527060

Salehi, S., Cotner, S., Azarin, S. M., Carlson, E. E., Driessen, M., Ferry, V. E., ... \& Ballen, C. J. (2019). Gender performance gaps across different assessment methods and the underlying mechanisms: The case of incoming preparation and test anxiety. Frontiers in Education, 4, 107. https://doi .org/10.3389/feduc.2019.00107

Schinske, J. N., Balke, V. L., Bangera, M. G., Bonney, K. M., Brownell, S. E., Carter, R. S., ... \& Fletcher, L. (2017). Broadening participation in biology education research: Engaging community college students and faculty. CBE-Life Sciences Education, 16(2), mr1.
Setren, E., Greenberg, K., Moore, O., \& Yankovich, M. (2019). Effects of the flipped classroom: Evidence from a randomized trial. (EdWorkingPaper: 19-113). Retrieved from Annenberg Institute at Brown University http:// www.edworkingpapers.com/ai19-113

Seymour, E., \& Hewitt, N. M. (1994). Talking about leaving: Factors contributing to high attrition rates among science, mathematics \& engineering undergraduate majors: Final report to the Alfred P. Sloan Foundation on an ethnographic inquiry at seven institutions. Boulder, CO: Ethnography and Assessment Research, Bureau of Sociological Research.

Snyder, J. J., Sloane, J. D., Dunk, R. D. P., \& Wiles, J. R. (2016). Peer-led team learning helps minority students succeed. PLoS Biol, 14(3), e1002398.

Steele, C. M. (1997). A threat in the air. How stereotypes shape intellectual identity and performance. American Psychology, 52(6), 613-629. Retrieved August 27, 2020, from www.ncbi.nlm.nih.gov/pubmed/ 9174398

Theobald, E. J., Hill, M. J., Tran, E., Agrawal, S., Arroyo, E. N., Behling, S., ... \& Dunster, G. (2020). Active learning narrows achievement gaps for underrepresented students in undergraduate science, technology, engineering, and math. Proceedings of the National Academy of Sciences USA 117(12), 6476-6483.

Trapani, J., \& Hale, K. (2019). Higher education in science and engineering: Science and engineering indicators 2020 (NSB-2019-7). Arlington, VA: National Science Foundation.

Williams, J., Phillips, K. W., \& Hall, E. V. (2014). Double jeopardy? Gender bias against women of color in science. San Francisco: Hastings College of the Law, Center for WorkLife Law.

Wilson, Z. S., Holmes, L., Sylvain, M. R., Batiste, L., Johnson, M., McGuire, S. Y., ... \& Warner, I. M. (2012). Hierarchical mentoring: A transformative strategy for improving diversity and retention in undergraduate STEM disciplines. Journal of Science Education and Technology, 21(1), 148156. 